\title{
Blockchain Paths in Rebooting the Global Response to the Sustainable Development Goals after COVID-19
}

\begin{abstract}
As we embrace the new normal in the aftermath of Covid-19, the year 2020 also marks the decade of action as we start the 10-year countdown to achieving the Sustainable Development Goals (SDGs) by 2030. In this paper, we attempt to explore the extent to which the hardly won development gains over the last years could be reversed due to the unfolding COVID-19 global pandemic, how do we reboot the global response to accelerate the SDGs in times of uncertainties, and most importantly how to turn the recovery into an opportunity to build back better and more resilient economies. To do so, we examine the case of blockchain as one of the emerging innovative work-streams in development practices that could lead the way forward and pave the path for new developmental narratives as we all navigate the uncharted territories of the new digital age.
\end{abstract}

Key Words: SDGs, Covid-19, Innovation, Blockchain, Development

Jel codes: O16, O19, O35, P16, Q01, Q56

\author{
Ahmet Faruk Aysan \\ Hamad Bin Khalifa University, \\ Professor \& Program Coordinator \\ $\mathrm{PhD}$ in Islamic Finance and Economy \\ College of Islamic Studies, \\ Qatar Foundation \\ P.O. Box: 5825, Education City, Doha, Qatar \\ aaysan@hbku.edu.qa
}

Fouad Bergigui

SDI Global Consult

f.bergigui@sdi.world 


\section{Blockchain Paths in Rebooting the Global Response to the Sustainable Development Goals after COVID-19}

\section{Introduction}

The comparative advantage of blockchain can be explained by its ability to address the issue of trust within the world financial system in the aftermath of the 2008 global financial crisis (Jiang, 2018). After COVID-19 pandemic, the globe will need even more trust for international cooperation and governance. Looking into the current practice among the key players in both worlds of public and permissioned blockchains, there is a costly race among early adopters towards becoming the standard and prototyping blockchain applications to do things other technologies simply cannot. Against this background, we can look at the blockchain as a package of technologies and approaches to open up new opportunities for users to manage transactions, exchange values, and maintain digital trust (Gartner, 2018). Blockchain applications that are designed in areas where trust is a must, yet hard to secure are predicted to prevail (Jiang, 2018).

In one forecast the business value of blockchain was predicted to climb up reaching $\$ 176$ billion by 2025 before skyrocketing to $\$ 3.1$ trillion by 2030 (Gartner, 2018). Nevertheless, blockchain is yet to deliver its promise to match the hype despite its potential. The maturity of blockchain technology is expected to facilitate its wider adoption, widen the scope for its utilization, and consequently foster blockchain's ability to stimulate successful disruptions. This goes in line with the need to stimulate business processes, enable regulatory frameworks, and trigger the necessary cultural shift and the underlying organizational structures.

Five years after the adoption of the Sustainable Development Goals (SDGs) in 2015 and 10 years ahead of the 2030 finish line, too many people's lives are reportedly changing for the worse (Ghosh, 2019). Now, if new technologies such as blockchain are going to contribute to solving the puzzle, there have to be adequate tools, methodologies, and standards to navigate the blockchain hype-cycle and move from a generalized "let's blockchain it" approach towards a rational narrative that is evidence-based. 
Despite blockchain's promising potential, the reality can be challenging, there are not enough data, blockchain-backed applications for social impact are under-studied, and claims that blockchain-backed solutions can yield superior results when compared to other alternatives are yet to be supported by evidence. While we can agree that blockchain has a promising potential to trigger disruptive innovations, we can also agree that the technology is not mature yet and that there is still a gap in terms of approaches and tools to develop blockchain use cases, evaluate blockchain applications, monitor experiments, mitigate associated risks and manage organizational changes to galvanize innovationreadiness within organizations considering to adopt blockchain technology and run use cases' experiments. It is only by filling the existing gaps that we can make a stronger case for using blockchain as an SDG accelerator.

Having these observations, we aim to unravel the best use cases implemented through blockchain. We analyze numerous applications of the blockchain implementations and categorize them under which SDGs that they contribute more. This approach is relatively new and much needed in the literature. Often times, blockchain applications are analyzed separately without relating them with a specific SDG. However, by analyzing an exhaustive list of blockchain applications and relating them with selected SGDs, we aim to guide the blockchain enthusiasts to be inspired with the new developmental ideas and thereby come up with their blockchains solutions for their community developments. As far as we know, this holistic approach in assessing the various blockchain applications has not been tried before. Our overall findings reveal that there are very practical blockchain applications exercised in different parts of the world. However, especially after COVID19 pandemic, the best use cases have the potential to be replicated in different parts of the world where the digital solutions are gaining importance with all sorts of Fintech and blockchain applications. The world is passing through a big digital transformation. Being in the middle of this transition, learning the narratives of each blockchain applications and relating these narratives with SDGs is the main narrative of this paper. Sustainability and SDGs need these new narratives in reshaping the post-Covid world.

The organization of the paper is as follows. In the next section, after talking briefly on the digitalization and SDGs, we delve into explaining the various blockchain applications and 
assess their potential for replications to serve reaching SDGs by 2010. In this part, we particularly focus on certain SDGs likely to benefit from the blockchain technology more namely SDG1-5, SGD8-9, and SDG16-17. In the last part, we depict our policy conclusions based on the evidences studied.

\section{Achieving the SDGs in the new digital age}

In this session, we navigate the disruptive waves brought by blockchain-powered solutions to exploring examples of experimental uses cases applicable to each of the 17 Sustainable Development Goals (SDGs). These experimentations zones are also complemented with an overview of specific acceleration areas, to have a closer look on areas where we believe blockchain-backed solutions can have a great impact as we are heading towards the uncharted territories of the post-pandemic era while eyeballing the finish line in the race to meeting the SDGs by 2030. We aim that individuals and organizations working on blockchain-based solutions for sustainable development utilize these insights and discussions to guide their efforts and inform their decisions to harness the disruptive potential of blockchain alone or in tandem with other emerging technologies in the new world of business as unusual.

The map in figure 2.1 shows a breakdown by region of the cumulative numbers of the SDGs to which blockchain projects for social impact contribute based on 71 entries listed in the Blockchain Ledger Impact database. This visualization suggests that East Asia and Pacific comes first as the region where blockchain projects contribute to the largest number of SDGs (Goldstein \& Tillemann, 2020). It's followed by North America, Europe, and Central Asia, Latin America and the Caribbean, Sub Saharan Africa, the Middle East and South Africa, and South Asia. While the map itself offers much-needed insights into the dynamics of the contribution made by blockchain-enabled solutions to the SDGs, it is only based on a limited number of blockchain projects for social impact $(n=71)$ and naturally falls short of providing the full picture.

This shows that blockchain-powered solutions remain largely understudied, which stresses the need for reliable sources of data to study how blockchain projects deliver or not, social impact on the ground (Goldstein \& Tillemann, 2020). Such insights are critical 
learning tools for organizations and individuals alike in an exciting but demanding journey to develop blockchain-backed solutions for social good.

Figure 2.1: Map showing the contribution of blockchain projects to the SDGs per region

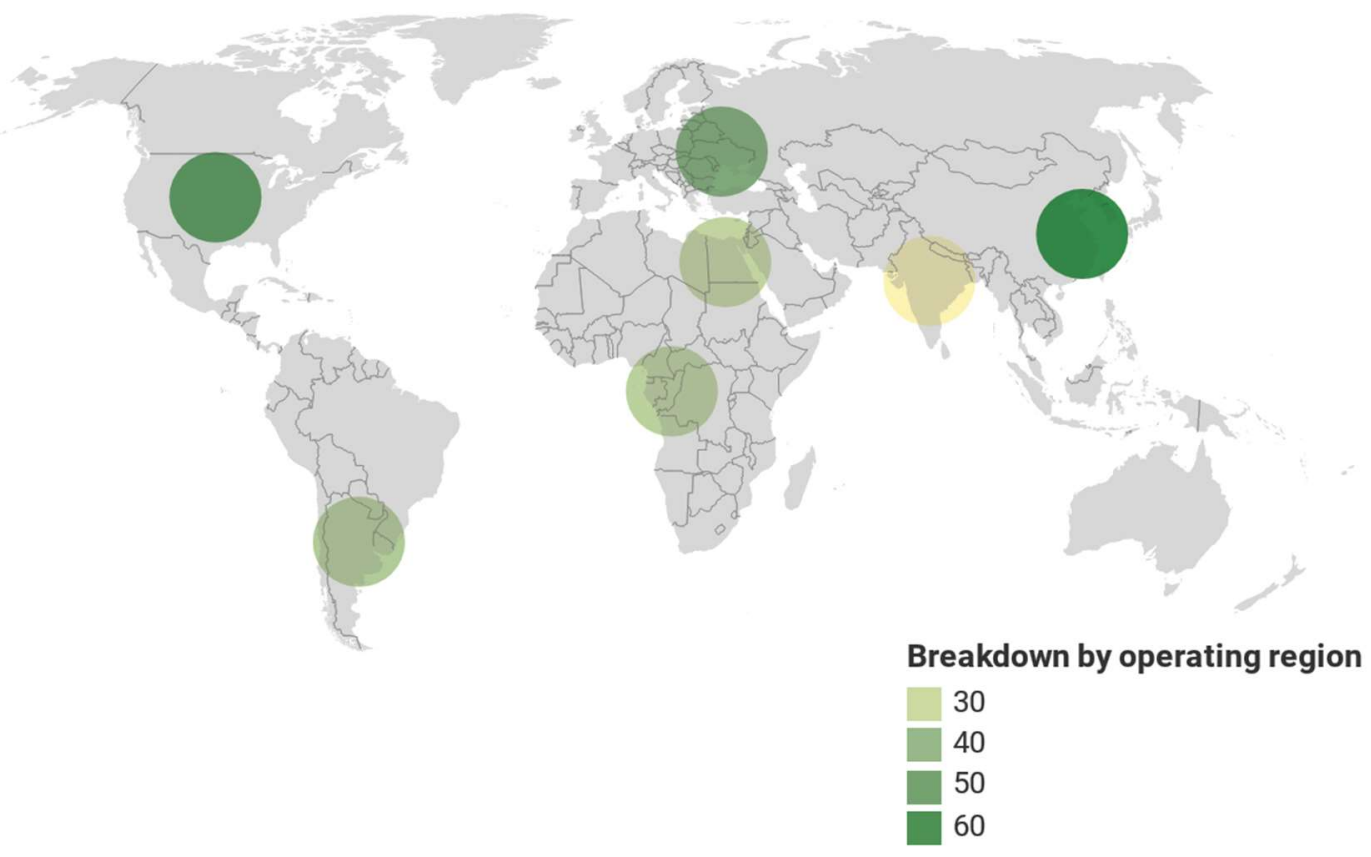

Source: Created by the author based on data from (Goldstein \& Tillemann, 2020)

There are multiple experiments, where tests are being conducted to explore the proof of concept to develop blockchain-backed solutions and address some of the most pressing challenges in global development. The fundamental question that comes in mind, is how can distributed ledger technologies be useful to solve a given situation which implies changing the narrative to re-think innovative ways out of the problem. For instance, to address identity-related issues, blockchain solutions were designed to provide digital economic identities (BanQu, 2019) or open identity systems (Uport, 2019). To ensure traceability and equity along supply-chains, blockchain applications are experimented to document the Cocoa's journey from the Amazonian farms in Ecuador to the grocery stores in the UK (AltFinLab, 2019), for tracing tuna fish from catch to consumers in Indonesia 
(Provenance, 2016), tracing the authenticity of diamonds (Everledger, 2018), or tracking minerals (Khatri, 2019).

In the field of energy, blockchain solutions are tailored to produce solar energy in Moldova using solar-coins (SolarCoin, 2019), or support the Cedar forest in Lebanon using Cedarcoins (AltFinLab, 2019). In the field of governance, blockchain applications are used in Estonia to run a digitalized e-government system on blockchain to ensure the security of government registers (Sihvart, 2017). In South Korea, blockchain solutions are tested to improve government services such as public safety, welfare, and transportation (Buck, 2017). Another experiment is looking into building peer-to-peer voting platforms to ensure transparency and accuracy (FollowMyVote, 2019). The list goes on and on to include various blockchain applications with relevance to global development such as copyright, social media, retail or real estate.

As shown in figure 2.2, SDG 16 (Peace, justice, and strong institutions) topped the list of the SDGs addressed by blockchain projects based on 71 entries listed in the Blockchain Impact Ledger (Goldstein \& Tillemann, 2020). It comes as no surprise to see blockchainenabled applications primarily deployed to address governance matters to tackle issues of transparency, fraud, and other unethical behaviors within a wide array of sectors within society. Earlier findings suggest that the scape for blockchain projects for social impact is still in its infancy as most projects are less than 2 years old, Ethereum is reportedly the most popular blockchain platform, and deploying the technology itself happens to be a multi-stakeholder process with projects consulting with 3-5 partners on average during product design and deployment (Gregori, 2019). 
Figure 2.2: Blockchain projects addressing each $S D G$

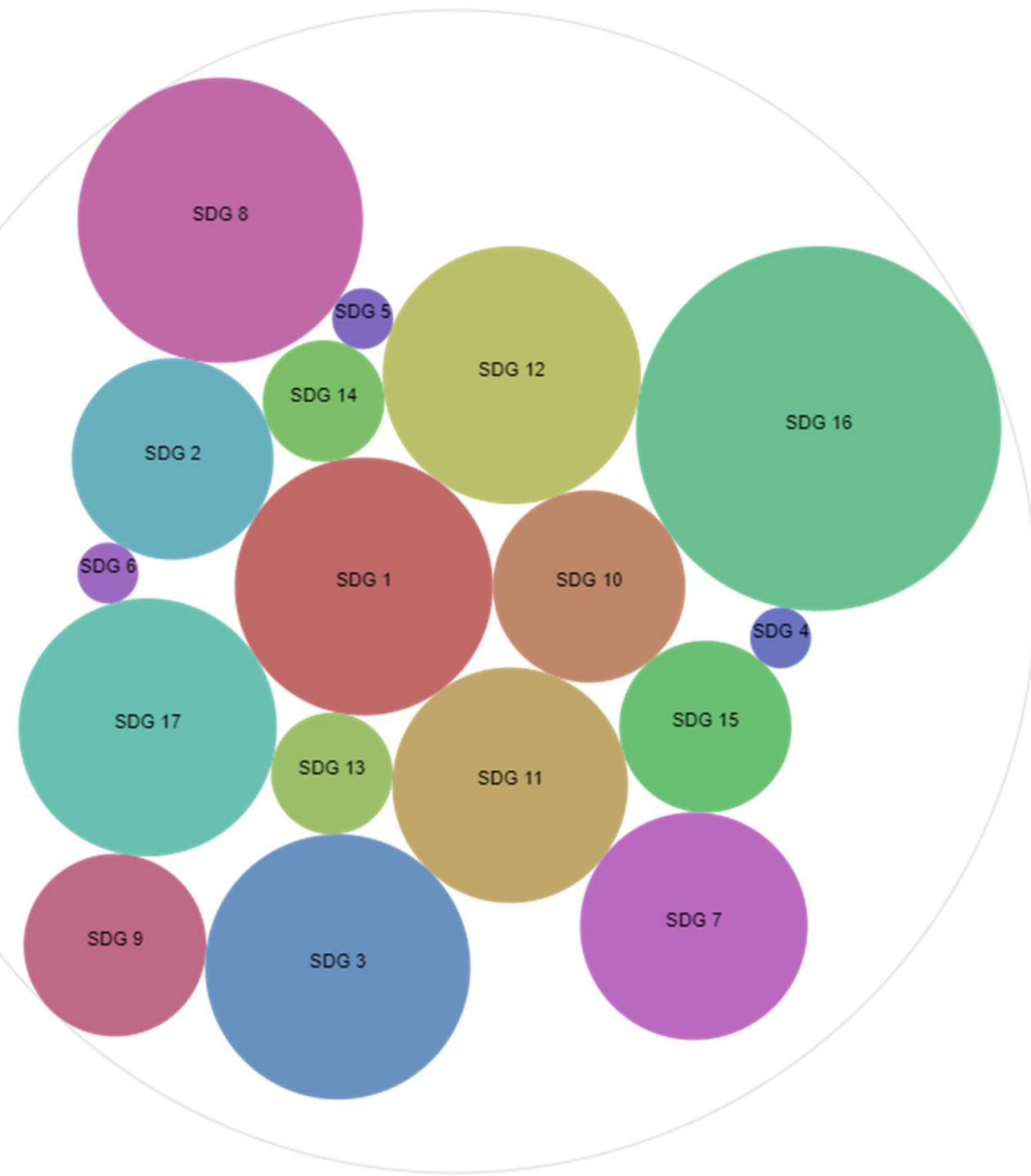

Source: Created by the author based on data from (Goldstein \& Tillemann, 2020)

Figure 2.3 shows a tree-map visualization of the contribution of blockchain-enabled solutions to each one of the 17 SDGs in East Asia and the Pacific, these findings are based on data related to 71 entries listed in the Blockchain Impact Ledger. Agora, for example, a blockchain-backed voting ecosystem allows people worldwide to vote online using a digital device while ensuring the security of elections and making it convenient for voters (Agora, 2019). It is reportedly contributing to two SDGs namely SDG 10 on reducing inequality within and among countries and SDG 16 on promoting peaceful and inclusive 
societies, providing access to justice, and building effective, accountable, and inclusive institutions. Such contribution spans across three regions namely East Asia and Pacific, North America, and Sub-Saharan Africa (Goldstein \& Tillemann, 2020).

Figure 2.3: Tree-map visualizing the contribution of blockchain-enabled solutions to the SDGs in East Asia and the Pacific

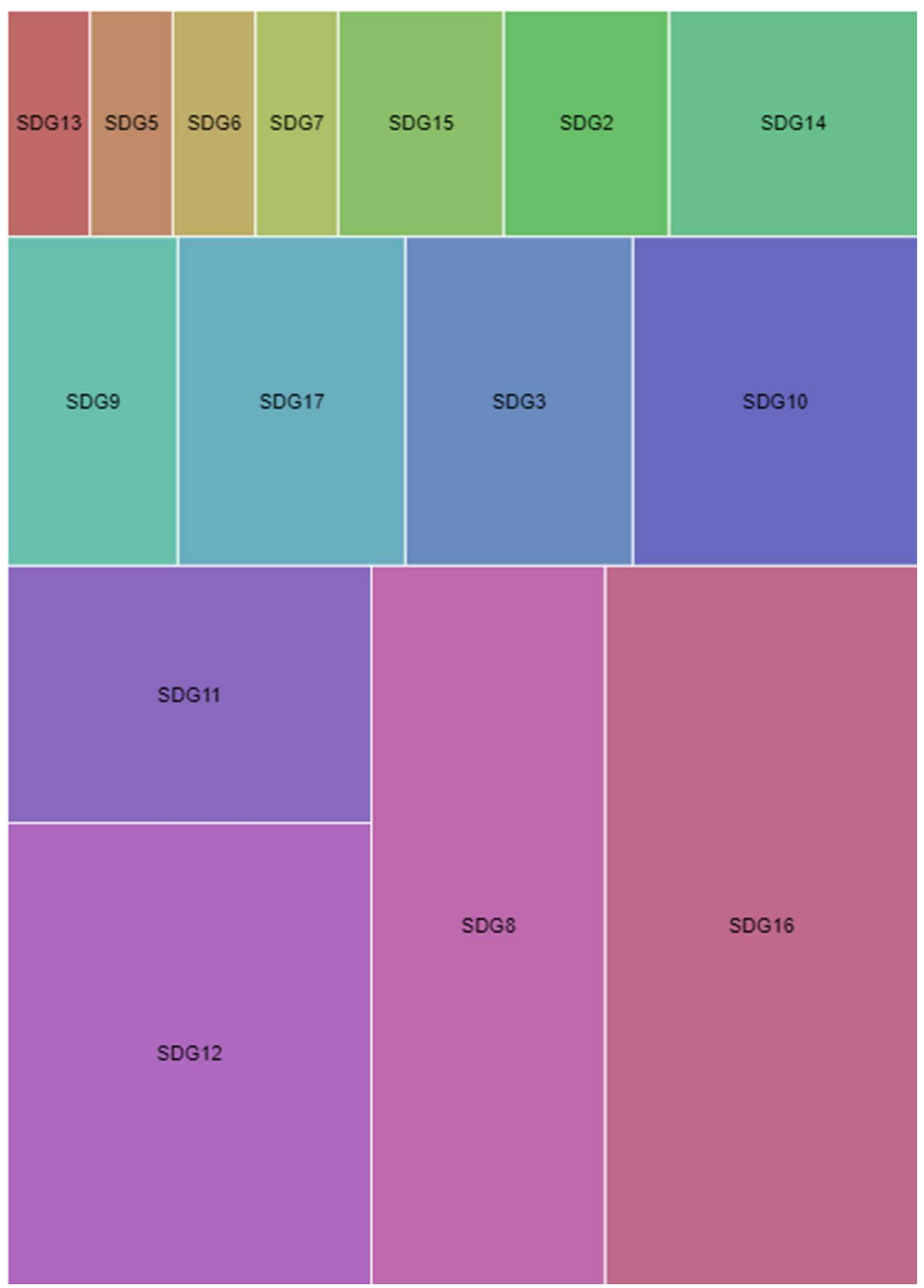

Source: Created by the authors based on data from (Goldstein \& Tillemann, 2020) 
This tree-map is the same visualization as the one above with the bubbles, but restricted to Est Asia Pacific

\section{SDG1: End poverty in all its forms everywhere}

With regards to eradicating poverty for instance, in 2015 during the transition from the MDGs to the SDGs, there were still about 736 million people surviving on less than USD 1.90 per day with more than $25 \%$ of the world's populations living on USD 3.20 and almost 50\% living below USD 5.50 daily (World Bank, 2018). In 2017, there were some 1.7 billion adults worldwide with no banking account, however, two-thirds of unbanked adults did have a mobile phone (World Bank Group, 2017). Although wealthier adults are more likely to own a phone and have access to the internet in contrast with their poorer counterparts, financial inclusion can be improved to lift the world's poorest and most vulnerable out of poverty by leveraging the new generation of financial services including blockchain-based solutions that could be accessed through mobile phones and internet. While it might not be profitable for the traditional banking system to offer services below a certain threshold, by processing micro-transactions via the blockchain the technology can connect smallholders and enable those usually overlooked to engage for instance in micro-trade or micro-lending. The tokenization of assets is disrupting the financial industry by making it more accessible, faster, cheaper, and easier (Laurent, Chollet, Burke, \& Seers, 2019).

In the Asia Pacific, the Asian Development Bank engaged Everest, a blockchain-based decentralized platform (Everest, 2020), to enable money transfer operators from Australia, New Zealand, and Samoa process cross border payments through the blockchain (Rheeney, 2019). By installing the Everest platform in the Samoan Central Bank, such a platform will support identify verification through biometrics, e-wallets, and compliance reporting including "Know Your Customer" and "Anti-Money Laundering” (Vilar, 2019). A similar project is taking place in Indonesia to facilitate cross-border remittance transactions along the Indonesia-Europe corridor in partnership with Bank Rakyat Indonesia (Ledger Insights, 2020). 
Another example comes from East Africa, where Kenya's famous and largely imitated mobile money system M-Pesa has reportedly lifted 194.000 households out of poverty, about $2 \%$ of the total households in Kenya (Suri \& Jack, 2016), despite its siloed nature which limits its impact. This is where blockchain technology can come into play to allow systems like M-Pesa seamlessly to interact with digital wallets, traditional bank accounts, and remittance services (Morris D. Z., 2020). This is the case of Mojaloop, the Swahili word for "One loop" (Mojaloop, 2020), an open-source global platform which can support real-time and interoperable digital payment systems in developing countries to increase financial inclusion (Hunter, 2020), and consequently uplift the world's poor out of poverty (ModusBox, 2017). The platform enables an 'internet of payments' through secure, lowcost, and interoperable payments using different components to bring bank accounts together with mobile money wallets and merchants in one loop, identify transaction accounts, ensure instant and irrevocable payment as well as protection against fraud (Cable, 2018).

\section{SDG2: End hunger, achieve food security and improved nutrition and promote sustainable agriculture}

Following a steady decline over the last decades, hunger is on the rise with more than 820 million people suffering from hunger in 2019, with Africa being the most hit continent showing the highest prevalence of undernourishment (FAO, 2019). In contrast, about 14\% of the food produced globally is lost during production or along the supply chain between harvest and retail (FAO, 2019), and about a third of the food produced for human consumption is lost or wasted, representing an estimated global volume of food wastage of about 1.6 gigatons (FAO, 2013) and putting its economic cost at about $\$ 1$ trillion every year (FAO, 2014).

Blockchain-based solutions can disrupt the global food value chain by tackling some of its inefficiencies. One way to optimize the supply-chain and tackle the opacity of the global food industry is by increasing transparency to sustainably mitigate food loss and 
wastage. Giving the interlinked nature of the SDGs, by addressing the supply chain in the food industry it will also contribute to reducing the carbon footprint of agriculture (SDG13), preserve biodiversity and ecosystems by reducing water consumption and soil contamination through the use of fertilizers and other chemicals (SDGs $14 \& 15$ ), and control the spread of food-borne diseases (SDG3).

Blockchain can be the platform to apply algorithms to match offer and demand while using valuable insights from behavioral sciences to predict consumption patterns, agriculture data, and remote sensing. This can enable the right amount of fresh harvest to make an optimal journey from the field, through processing to retail, by tracking every step of the value chain including the production and harvesting techniques, storage protocols, transportation, processing, and distribution. The same thinking can be applied to humanitarian food aid, for instance, to ensure the transparency of cash transfers and enable refugees to purchase food.

AgriLedger, created under $48 \mathrm{~h}$ in a hackathon then tweaked to become part of the Agtech landscape (AgriLedger, 2017), is a seed-to-customer blockchain-enabled platform offering end-to-end traceability along agricultural value chains (Leveille, 2019) which aims to democratize agricultural data using blockchain (Aspioneer, 2018). A pilot project with the World Bank along the fruits value chain in Haiti, allows buyers to scan a QR code to tell the story of the fresh mango produce by revealing the tree it came from, where it was packaged and how it was transported, and the costs incurred at each milestone. The immutable data related to registration, certification, and sale documents are made easily accessible on the web and via smartphone (Leveille, 2019).

In Ethiopia's Limu region, Token, a new consumer brand of coffee or rather a blockchain coffee, is a blockchain-powered solution that aims to connect coffee growers and consumers (Bryman, 2018). While such an application contributes to transparency and traceability, it may also strengthen ownership. Token coffee bags come with a token that is worth 50 cents of a Euro which represents its marketing cost. Coffee consumers can then use the CrypCore platform (KrypC, 2019) to invest their tokens whether by 
discounting the price of the coffee they bought, by supporting coffee producers, or the brand itself. The proof of concept was based on an initial experiment covering $60,000 \mathrm{Kg}$ of coffee produced by smallholder communities, and the tokenization was initially tested with about 100 individuals (FoodIngredientsFirst, 2018).

Again, this shows how the SDGs are interlinked. By paying a more just and equitable price to smallholder farmers, they can afford the cost of production while preserving their social and environmental capitals in the long run.

\section{SDG3: Ensure healthy lives and promote well-being for all at all ages}

In the healthcare industry, blockchain use cases range from record management to surveillance systems, streamlining communication, tracking outbreaks, managing crises, tracking medical supply chains, preventing zoonotic diseases, and providing genomic services. Mutual health plans and insurance firms can offer accessible insurance products to low-income groups and expedite payments to participants by eliminating paperwork and easing verification of claims.

Alipay's Xiang $\mathrm{Hu}$ Bao, an online blockchain-backed mutual aid platform that complements premium health insurance plans. The online system publicly discloses claims on the blockchain and facilitates the digital authentication of official documents (Ant Financial, 2019). Its coverage includes 100 critical illnesses, there are no premiums to be paid, participants share the cost of claims made and contribute to payouts, and the approved claims may entitle participants to a one-time payout of up to roughly US\$44.000 (Ledger Insights, 2019). In Hong Kong, Blue Cross Asia-Pacific Insurance was able to handle over 1000 simultaneous transactions in one second through its blockchain-based platform with no human interaction, by shortening the time spent on paperwork, blockchain can ease the pressure on health care systems (Tran, 2020).

In Estonia, a blockchain-backed solution by Guardtime will enable an audit trail through the lifecycle of patients' records making data virtually impossible to manipulate (E- 
estonia, 2016). Patientory is a platform to store, manage, and transfer private health information including through the execution of smart contracts on the Ethereum blockchain (Patientory, 2020). In the field of genomics, Nebula Genomics provides a blockchain platform to conduct free DNA sequencing in exchange for consent for the data to be used in research (Morris N. , 2018).

During the global pandemic of COVID-19, as the world struggled to cope with a health crisis with far-reaching consequences on the economy and long-lasting impacts on different aspects of human life, different blockchain-based solutions emerged. Panic buying and inflation for instance could be interpreted as signs of poor trust in institutions in charge of keeping people safe. In supply chains, for instance, blockchain was used to trace and confirm the source of products and information to fight counterfeit production and misinformation. It can also play a role in minimizing price inflation by ensuring a transparent cost distribution.

Acoer created the HashLog data visualization engine, a blockchain-enabled dashboard to track and map out vital health information and enable professionals in the healthcare and life science space track and visualize the outbreak (Nasr, 2020). Shanzong launched a blockchain-based platform to ensure the efficiency and transparency of donations, it tracked which donations were made from money to medical equipment, how they were matched, and delivered during the Coronavirus pandemic (Zhang, 2020). Other blockchain-powered solutions during COVID-19 include e-learning platforms (Humayun, 2020) and decentralized learning certificates (Hayward, 2020).

\section{SDG4: Ensure inclusive and equitable quality education and promote lifelong learning opportunities for all}

In the areas of education and lifelong learning, blockchain can be used to store records, secure students' identities and credentials, transfer credits, increase the efficiency of existing business-processes, process students' payments and grants, protect and track the use of the intellectual property for educational content. This will reduce costs and fraud 
by skipping manual verification of degrees and transcripts while increasing efficiencies through automated smart contracts (Cognizant, 2019).

ODEM, a blockchain-powered education platform, offers a decentralized education scheme within which students, educators, and schools operate autonomously while enjoying full control over their educational data and employment records (ODEM, 2020). It provides a secure solution for integrated enrollment, learning management, in addition to blockchain-backed digital learning certificates which can be used to track progress and achievements (ODEM.IO, 2020). Such a blockchain-based solution empowers students to take full ownership of their educational records. Not only can they select courses according to employer demand, but they also will not have to wait for hard diplomas to be delivered to apply for jobs or need to replace originals if they get lost or damaged (Maaghul, 2019).

Digital Academic Credentials, an MIT incubated project (MIT Media Lab, 2016), allowed students to receive tamper-proof and verifiable digital diplomas on their smartphones using the Blockcerts Wallet app on the bitcoin blockchain (Trachy \& Durant, 2017). Using the same open-source code in the Asia Pacific, the University of Melbourne issued recipient-owned digital credentials on the blockchain in an attempt to tackle the challenges raised by increasingly itinerant students and workforce (UoM, 2017).

\section{SDG5: Achieve gender equality and empower all women and girls}

Gender equality is not just about SDG5, it is central to the achievement of all the SDGs. Empowering women and men will not only contribute to the global economy, lift entire families and rural communities out of poverty but also accelerate national efforts on different frontlines by promoting all sorts of gender-smart, gender-responsive and gendersensitive interventions in the economy, climate change, biodiversity conservation, education, innovation, and other areas pertaining to the wider spectrum of the Sustainable Development Agenda. Blockchain can disrupt the way financial services are provided to the most vulnerable groups which remain underbanked and largely excluded from the 
traditional financial markets. More specifically, women in developing countries are most likely to earn their income from the informal sector and suffer from financial illiteracy, mobility constraints, insufficient collaterals, or even the lack of identification. Blockchain can bridge the gender gap in cross-border payments and empower women and men to fulfill their financial independence.

UN Women is exploring blockchain-enabled solutions to support the humanitarian response targeting women and girls in emergencies such as refugees to secure their identity, medical, and asset ownership records (UN Women, 2018). Among the innovations showcased is SPENN (Blockbonds, 2019), a digital wallet that enables users to interact with each other using their smartphones to receive, save, transfer and spend money (Young \& Hammond, 2018). In refugee camps, such solutions can remove the need for women to carry physical cash and empower them to have greater control over their financial resources. In Vietnam, the World Bank is testing a blockchain-backed pilot to support women entrepreneurs prove asset ownership, verify production values, and establish digital identities (Young \& Hammond, 2018).

From Norway, a blockchain application called VipiCash was developed not only to securely transfer money and reduce transfer costs but also to enable women in the refugee camps to decide on how it will be spent independently from men in their families. By locking the money for a specific use, for instance, to buy groceries or pay for school fees, a Congo born winner of the Nordic Startup Awards wanted to help refugees in Malawi to avoid frictions between men and women and ensure that remittances are used for what they are intended for (UN Women, 2018). This blockchain solution faced challenges to overcome biases and get access to resource persons who can help grew up the idea (SWB, 2018).

Hiveonline, a company using blockchain-backed solutions to support underserved microbusinesses access credit and markets by creating a trusted history for formal reputation, has launched its community finance platform eARZIKI in Niger, targeting village savings and loans groups to enable women to grow their businesses through formal reputation and 
access to finance (Blakstad, 2019). It digitizes money and identities, boosting thus the trustworthiness of micro-entrepreneurs seeking to borrow funds. Activities such as attending meetings and payments made are recorded to prove the borrowers reliable to the lenders and vice versa, meaning that lenders are also rated based on their reliability and how they treat customers (CWI, 2020).

It is true however that the gender divide extends its branches over the digital walls to the crypto space, with the management of crypto-firms being mostly men-dominated and few women trading in crypto-assets. The transformational change will also need to start from within the crypto industry itself. There is a need to invest in the skills sets women and other social groups from all walks of life need to enter the crypto space as coders, developers, data scientists, mentors, or managers. Diversity in Blockchain, an NGO working to empower individuals to equally engage with the blockchain technology, highlighted the lack of inclusion in its State of Diversity and Inclusion in Blockchain report (Tinianow, 2019). The report recommended in its call for action to implement best practices such as training on unconscious biases, measuring and reporting diversity and inclusion, and creating policies of openness and trust (Joseph, 2019). Ironically, while blockchain can foster trust, it also needs to bolster policies of trust, and while it can empower women and men to challenge gender inequalities, it also needs to become gender-responsive.

\section{SDG8: Promote sustained, inclusive, and sustainable economic growth, full and productive employment, and decent work for all}

Economic growth and employment can also benefit from disruptive technologies such as Blockchain, which is seen by some as the new infrastructure for building efficient ecosystems to spark innovation across various economic sectors and achieve growth, enable countries to tap into their demographic dividends, create qualified jobs in the crypto sphere and facilitate recruitment processes. 
In the Background Check industry, the current business model is relatively slow, involving multiple personnel and does neither guarantee successful screenings nor the security of sensitive data. CVerification, a blockchain-based platform, offers a new way for corporations and recruitment agents to headhunt the most promising candidates through a blockchain-backed and direct exchange of employment records and academic references. The platform also supports the verification of various educational records while providing useful analytical tools to track important insights related to the employment markets (CVerification, 2017).

\section{SDG9: Build resilient infrastructure, promote inclusive and sustainable industrialization, and foster innovation}

Blockchain applications can spark innovation across a wide spectrum of industries from automotive to banking, health care, insurance, media and entertainment, retail and consumer goods, travel, and transportation to name just a few examples.

In the automotive industry, for instance, cars can become much more than vehicles in the rapidly evolving landscape of smart mobility and evolve into some sort of connected software on wheels. This is the case made by IBM and partners developing a blockchainbased eWallet to handle cashless payments from tolls to electric charging, but also between cars and the use of a vehicle's trunk to securely drop a package (IBM, 2018).

\section{SDG 11: Make cities and human settlements inclusive, safe, resilient, and sustainable}

The next-generation infrastructure for smart cities can be built on blockchain layers to come up with disruptive solutions to tackle pressing issues such as waste management, protection of personal data, strategic urban planning, green energy, public participation, low carbon transportation, water management, health systems, traffic management and the security of IoT devices. 
In Malta, the Government is developing a platform for transport and logistics to proactively predict growth, balance routes, and systems, and optimize services based on passenger' behavior by using blockchain-backed data flows such as GPS systems, and journey tracking (Omnitude, 2018). In Estonia, the Government created the concept of eresidency, invested in digital IDs and cybersecurity, and established data embassies abroad with blockchain-backed State registries including healthcare, property, succession, and business in addition to the digital court system and the state Gazette (PWC, 2019).

\section{SDG 16: Promote peaceful and inclusive societies for sustainable development, provide access to justice for all, and build effective, accountable, and inclusive institutions at all levels}

It comes as no surprise to see blockchain-enabled applications primarily deployed to address governance matters and to tackle issues of transparency, fraud, and other unethical behaviors within a wide array of sectors within society. These are the very foundations to ensure peaceful and inclusive societies, accountability, and justice. Giving the secure and immutable nature of the blockchain technology, SDG 16 topped the list of the SDGs addressed by blockchain projects based on 71 entries listed in the Blockchain Impact Ledger (Goldstein \& Tillemann, 2020).

Civil, a blockchain-backed network for journalists, news organizations, and investors, offers a combination of tokens and voting rights to its shareholders. Participants hold a blockchain-based token to govern the network, they can vote and propose rules. The platform also features a micropayment enabling journalists to receive donations from readers in the form of tokens which forms a substantial part of their salaries and makes reporters also shareholders of Civil (Ivancsics, 2019). Blockchain use cases in journalism can be targeted solutions to store data or hybrids introducing cryptocurrency which may disrupt the way newsrooms and reports work (Ivancsics, 2019). Some argue however that blockchain will not save journalism and that the hype around the technology is driving incomprehensible applications (Jonah, 2018). 


\section{SDG 17: Strengthen the means of implementation and revitalize the global partnership for sustainable development}

One key issue to achieve the Sustainable Development Goals (SDGs) is indeed financing for development which remains way below expectations especially in developing countries. While public finance and Official Development Assistance will not be enough to fill in the financing gap, achieving the SDGs cannot be done without securing business financial flows.

Blockchain backed solutions can improve the financial infrastructure for international development and humanitarian aid. Trócaire Ireland, a development agency, simultaneously transferred $€ 10,000$, via Trócaire Rwanda, to Caritas Rwanda using the Disberse platform, and $€ 10,000$ via their regular banking channel. The transfer via Disberse incurred no additional charges; the parallel transfer through the banking system incurred at least one additional charge of EUR35. In this pilot, Disberse did not charge transaction fees, but a small fee will be considered in the future. There was clear tracking of the Disberse financial transfers. The transactions were transparent and accountable to each stakeholder in the transaction chain. Transactions were timestamped and created a viewable trail. There were challenges in comparing time savings measured by the number of working days it took funds to move from Trócaire Ireland to Caritas Rwanda, the banking system took 6 days, while Disberse took 5 days (Start Network, 2018). Table 2.1 summarizes the blockchain-enabled solutions mapped out in this paper in terms of their potential contributions to the SDGs. 
Table 2.1: Blockchain-enabled solutions and their potential contributions to the SDGs

\begin{tabular}{|c|c|c|}
\hline SDGs & Blockchain-enabled solutions & What is it used for? \\
\hline \multirow[t]{3}{*}{ SDG1 } & Asian Development Bank \& partners & Cross border payments \\
\hline & M-Pesa & Mobile money system \\
\hline & Mojaloop & Digital payment system \\
\hline \multirow[t]{2}{*}{ SDG2 } & AgriLedger & Seed-to-customer platform \\
\hline & Token & Coffee value chain \\
\hline \multirow[t]{7}{*}{ SDG3 } & Xiang Hu Bao & Mutual aid platform \\
\hline & Blue Cross Asia-Pacific & Health insurance \\
\hline & E-estonia & Patients' records \\
\hline & Patientory & Health records \\
\hline & Nebula Genomics & Dna sequencing \\
\hline & HashLog & Data visualization engine \\
\hline & Shanzong & Donations platform \\
\hline \multirow[t]{3}{*}{ SDG4 } & ODEM & Education platform \\
\hline & MIT Media Lab & Digital credentials \\
\hline & University of Melbourne & Digital credentials \\
\hline \multirow[t]{4}{*}{ SDG6 } & SPENN & Digital wallet \\
\hline & World Bank pilot in Vietnam & Asset ownership \\
\hline & VipiCash & Money transfer \\
\hline & eARZIKI & Community finance platform \\
\hline SDG8 & CVerification & Records and references \\
\hline SDG9 & IBM and partners & Ewallet \\
\hline \multirow[t]{2}{*}{ SDG11 } & Government of Malta & Transport and logistics \\
\hline & Governement of Estonia & Data registeries \\
\hline SDG16 & Civil & Network for journalism \\
\hline SDG17 & Disberse platform & Money transfer \\
\hline
\end{tabular}

Source: Authors 


\section{Concluding remarks and discussions}

Could blockchain be a game-changer as an SDG accelerator under a new normal scenario? Or is it a hype that is driven by high expectations for its applications in the new digital age? We argue that the power of blockchain can be effectively harnessed to deliver significant progress towards achieving the SDGs. Nevertheless, we also argue that there are limitations to what can be done, hence the need to nuance that development professionals cannot solve all the issues around the SDGs with blockchain, and that implementation choices to design and implement blockchain-enabled solutions should be rigorously justified to demonstrate a tangible added-value compared to other alternative solutions which might be less costly and less technical.

While we recognize the limitations in developing the Blockchain SDG Acceleration Scorecard and the Integrated Approach to use blockchain enable solutions as SDG accelerators, these are meant to be minimally viable products and serve as living tools making room for further improvements and fine-tuning as the technology is getting mature and lessons learned from various experiments widely shared across the international development space.

“Don't over-hype" and don't over-promise", remains indeed a key message for individuals and organizations experimenting blockchain-powered solutions in International development. In this paper, we aim to offer good food for thought to further stimulate the discussions within the research community but also among innovation and development practitioners working at the frontlines to raise the double challenge of adapting to the new normal post-pandemic and meeting the SDG targets by 2030.

Certainly, this work only scratched the tip of the blockchain iceberg. Its hidden part will only emerge over time, as the technology is getting mature and lessons learned are being shared based on the trial and error experiments being conducted within various geographies and across a wide range of economic, social, and environmental spectrums. 


\section{References}

Agora. (2019). Bringing voting systems into the digital age. (Swiss Lab \& Foundation for Digital Democracy) Retrieved 5 29, 2020, from https:/www.agora.vote/

AgriLedger. (2017). Are you ready for the Agtech revolution? Retrieved 5 30, 2020, from http://www.agriledger.io/about/

AltFinLab. (2019). A fair deal for Ecuadorian cocoa farmers. Retrieved from Alternative Financing Lab. Retrieved 5 10, 2020, from https://altfinlab.org/blog/a-fair-dealfor-ecuadorian-cocoa-farmers

AltFinLab. (2019). Adopting a cedar tree brings diaspora money home. Retrieved from Alternative Financing Lab: Retrieved 5 10, 2020, from https://altfinlab.org/blog/adopting-a-cedar-tree-brings-diaspora-money-home

Ant Financial. (2019). Alipay's Xiang Hu Bao aims to provide online mutual aid to 300 million people in the next 2 years. Retrieved 5 31, 2020, from Ant Financial Services Group: https://www.antfin.com/newsDetail.html?id=5caeea701d75d2d441311eba

Aspioneer. (2018). AgriLedger, Democratizing Agriculture Data using Blockchain. Retrieved 5 30, 2020, from https://aspioneer.com/agriledger-democratizingagriculture-data-using-blockchain/

BanQu. (2019). Dignity Through Identity. Retrieved 5 10, 2020, from https://banqu.co/the-tech/

Blakstad, S. (2019). Launching eARZIKI - Blockchain Financial Inclusion - in Niger with M. Le President. Retrieved 5 31, 2020, from Hivenetwork: https://www.hivenetwork.online/2019/07/launching-e-arziki-in-niger-with-m-lepresident-de-la-republic/

Blockbonds. (2019). SPENN. Retrieved 5 31, 2020, from https://blockbonds.io/spenn

Bryman, H. (2018). Fully Blockchained Coffee Brand Token Invites Consumers Into the Matrix. Retrieved 5 30, 2020, from Daily Coffee News: https://dailycoffeenews.com/2018/07/11/fully-blockchained-coffee-brand-tokeninvites-consumers-into-the-matrix/

Buck, J. (2017, 5 30). Samsung Wins Public Sector Blockchain Contract For Korean Gov't. Retrieved from Cointelegraph: https://cointelegraph.com/news/samsungwins-public-sector-blockchain-contract-for-korean-govt 
Burgess, B., \& Turner, J. (2019). Estimating Financing to the Sustainable Development Goals: Methodology Note for V2.0. Retrieved 5 24, 2020, from https://www.aiddata.org/publications/estimating-financing-to-the-sustainabledevelopment-goals-version-2-0

Cable, E. (2018). Webinar: Introduction to Mojaloop from the Gates Foundation. Retrieved from Mifos: https://mifos.org/blog/intro-to-mojaloop/

Cognizant. (2019). Blockchain Goes to School. Retrieved April 2, 2020, from https://www.cognizant.com/whitepapers/blockchain-goes-to-schoolcodex3775.pdf

CVerification. (2017). Blockchain-based Recruitment and Background Verification Platform. Retrieved 5 7, 2020, from https://icorating.com/upload/whitepaper/v8AtWVXJCAjwZzrLNhVUEJwG3E5 VakbMaqIUgtpw.pdf

CWI. (2020). Finalist 2020 Europe. Retrieved 5 31, 2020, from Cartier Women's Initiative: https://www.cartierwomensinitiative.com/candidate/sofie-blakstad

E-estonia. (2016). eHealth authority partners with Guardtime to accelerate transparency and auditability in health care. Retrieved 5 31, 2020, from https://eestonia.com/ehealth-authority-partners-with-guardtime-to-acceleratetransparency-and-auditability-in-health-care/

Everest. (2020). Fintech Elevating Humanity. Retrieved 5 30, 2020, from Everest: https://everest.org/\#the-project

Everledger. (2018). Do You Know Your Diamond? Retrieved 5 10, 2020, from https://diamonds.everledger.io/

FAO. (2013). Food wastage footprint, impacts on natural resources. Retrieved March 16, 2020, from http://www.fao.org/3/i3347e/i3347e.pdf

FAO. (2014). Food wastage footprint, full cost accounting. Retrieved March 16, 2020, from http://www.fao.org/3/a-i3991e.pdf

FAO. (2019). The state of food and agriculture. Retrieved March 16, 2020, from http://www.fao.org/3/ca6030en/ca6030en.pdf

FAO. (2019). The state of food security and nutrition in the world. Retrieved March 16, 2020, from http://www.fao.org/3/ca5162en/ca5162en.pdf 
FollowMyVote. (2019). Introducing a secure and transparent online voting solution for the modern age. Retrieved 5 10, 2020, from https://followmyvote.com/

FoodIngredientsFirst. (2018). Blockchain coffee: Token builds a "community-owned" coffee brand. Retrieved 5 30, 2020, from Food Ingredients First: https://www.foodingredientsfirst.com/news/blockchain-coffee-token-builds-acommunity-owned-coffee-brand.html

Gartner. (2018). Digital Disruption Profile: Blockchain's Radical Promise Spans Business and Society. $\quad$ Retrieved 29, 2020, from https://www.gartner.com/en/doc/3855708-digital-disruption-profile-blockchainsradical-promise-spans-business-and-society

Ghosh, J. (2019). 3 obstacles that stand in the way of the UN's Sustainable Development Goals. $\quad$ Retrieved 5 24, 2020, from WEF: https://www.weforum.org/agenda/2019/09/3-obstacles-that-stand-in-the-way-ofthe-un-s-sustainable-development-goals/

Goldstein, D., \& Tillemann, T. (2020). Blockchain Impact Ledger. Retrieved 5 22, 2020, from New America: https://www.newamerica.org/digital-impact-governanceinititiative/blockchain-trust-accelerator/reports/blockchain-impact-ledger/

Hayward, A. (2020). Coronavirus is driving education onto blockchain. Retrieved 531 , 2020, from https://decrypt.co/24785/coronavirus-is-driving-education-ontoblockchain

Humayun, M. (2020). Blockchain-Based secure framework for e-learning during COVID19. Indian Journal of Science and Technology. Retrieved 5 31, 2020, from https://www.researchgate.net/publication/341263802_Blockchain-

Based_secure_framework_for_e-learning_during_COVID-

19/link/5eb6118a4585152169c1020b/download

Hunter, P. (2020). Nonprofits and Tech companies unite to launch Mojaloop Foundation for Financial Inclusion. Retrieved 5 30, 2020, from IBS Intelligence: https://ibsintelligence.com/ibs-journal/ibs-news/nonprofits-and-tech-companiesunite-to-launch-mojaloop-foundation-for-financial-inclusion/

IBM. (2018). Drive your automotive enterprise forward with IBM blockchain. Retrieved 5 8, 2020, from https://www.ibm.com/downloads/cas/D9KWXMDW

Ivancsics, B. (2019). Blockchain in Journalism. Retrieved 5 31, 2020, from Columbia Journalism Review: https://www.cjr.org/tow_center_reports/blockchain-injournalism.php 
Jiang, L. (2018, December 13). The Age of Trust - the problem blockchain solves that others cannot. Retrieved September 24, 2019, from https://medium.com/swlh/theage-of-trust-the-problem-blockchain-solves-that-others-cannot-6024ebf47cad

Jonah, B. E. (2018). Alas, the Blockchain Won't Save Journalism After All. Retrieved 5 31, 2020, from The New York Times: https://www.nytimes.com/2018/11/01/style/blockchain-journalism-civil.html

Joseph, S. (2019). State of Diversity and Inclusion in Blockchain. Retrieved 5 31, 2020, from

https://static1.squarespace.com/static/5a7f13828a02c7e2df8e6c68/t/5e00f58ccf1 $18 \mathrm{~b} 46 \mathrm{~b} 6 \mathrm{fbd} 32 \mathrm{c} / 1577121230490 /$ The + State + of + Diversity + and + Inclusion + in + Bl ockchain.pdf

Khatri, Y. (2019). Volkswagen to Track Minerals Supply Chains Using IBM Blockchain. Retrieved 5 10, 2020, from CoinDesk: https://www.coindesk.com/volkswagen-totrack-minerals-supply-chains-using-ibm-blockchain

KrypC. (2019). Unlock the potential of Blockchain innovation. Retrieved 5 30, 2020, from https://krypc.com/

Lafortune, G. (2020). Europe Sustainable Development Report. Sustainable Development Solutions Network. Retrieved 5 24, 2020, from https://irpcdn.multiscreensite.com/6f2c9f57/files/uploaded/ESDR\%20Highlights.pdf

Laurent, P., Chollet, T., Burke, M., \& Seers, T. (2019). The Tokenization of Assets is Disrupting the Financial Industry. Are You Ready? Deloitte. Retrieved 5 30, 2020 , from https://www2.deloitte.com/content/dam/Deloitte/lu/Documents/financialservices/lu-tokenization-of-assets-disrupting-financial-industry.pdf

Ledger Insights. (2019). Alipay's blockchain mutual health plan attracts 50 million users. Retrieved 5 31, 2020, from https://www.ledgerinsights.com/alipays-blockchainmutual-health-plan-attracts-50-million-users/

Ledger Insights. (2020). Everest partners with Bank Rakyat Indonesia for remittances using blockchain. Retrieved 5 30, 2020, from https://www.ledgerinsights.com/blockchain-remittance-everest-bank-rakyatindonesia/

Leveille, G. (2019). World Bank blockchain pilot sows fresh narrative for Haiti's farmers. Retrieved 5 30, 2020, from Open Access Government: https://www.openaccessgovernment.org/world-bank-blockchain-haitisfarmers/61205/ 
Maaghul, R. (2019). It's 2019, And You Should Be in Control of Your Education. Retrieved 5 31, 2020, from https://blogs.odem.io/odem-blockchain-technologyand-unlocking-your-education

MIT Media Lab. (2016). What we learned from designing an academic certificates system on the blockchain. Retrieved 5 31, 2020, from Medium: https://medium.com/mitmedia-lab/what-we-learned-from-designing-an-academic-certificates-system-onthe-blockchain-34ba5874f196

ModusBox. (2017). Announcing Mojaloop.io - An Open-Source Software Platform for Financial Inclusion to Uplift the World's Poor. Retrieved from 30

Mojaloop. (2020). Open Source Software Empowering Organizations to Create Interoperable Digital Payment Systems to Increase Financial Inclusion. Retrieved 5 30, 2020, from Mojaloop Foundation: https://mojaloop.io/the-mojaloopfoundation-launches-as-a-charitable-nonprofit-organization-to-advance-thefinancial-inclusion-mission-of-mojaloop/

Morris, D. Z. (2020). Google and Gates Foundation to help spread digital payments in developing countries. Retrieved 5 30, 2020, from Fortune: https://fortune.com/2020/05/06/google-gates-foundation-digital-paymentsdeveloping-countries/

Morris, N. (2018). Nebula launches "free” DNA sequencing blockchain platform. Retrieved $31 \quad 5, \quad 2020$, from Ledger Insights: https://www.ledgerinsights.com/nebula-launches-dna-blockchain-platform/

Nasr, J. (2020). Acoer: We Track Coronavirus on Blockchain. Retrieved from Digital Asset Live: https://digitalasset.live/2020/02/05/blockchain-coronavirusinterview/

ODEM. (2020). The ODEM Trust Network. Retrieved 5 31, 2020, from https:/odem.io/odem-trust-network/

ODEM.IO. (2020). ODEM helps fight Coronavirus by offering its Blockchain Education and Credentialing platform for free. Retrieved 5 31, 2020, from PR Newswire: https://www.prnewswire.com/news-releases/odem-helps-fight-coronavirus-byoffering-its-blockchain-education-and-credentialing-platform-for-free301019428.html

Omnitude. (2018). Omnitude \& The Maltese Govt. Retrieved 5 8, 2020, from https:/omnitude.tech/omnitude-the-maltese-govt/ 
Patientory. (2020). Your health, at your fingertips. Retrieved 5 31, 2020, from https://patientory.com/

Provenance. (2016). From shore to plate: Tracking tuna on the blockchain. Retrieved 5 10, 2020, from https://www.provenance.org/tracking-tuna-on-the-blockchain

PWC. (2019). Estonia - the Digital Republic Secured by Blockchain. Retrieved 5 8, 2020, from https://www.pwc.com/gx/en/services/legal/tech/assets/estonia-the-digitalrepublic-secured-by-blockchain.pdf

Rheeney, A. (2019). Firm engaged to support money transfer operators. Retrieved 530 , 2020, from Samoa Observer: https://www.samoaobserver.ws/category/article/40817

Runde, D., Metzger, C., \& F. Abdullah, H. (2020). Covid-19 Demands Innovative Ideas for Financing the SDGs. Retrieved 5 24, 2020, from Center for Strategic and International Studies: https://www.csis.org/analysis/covid-19-demandsinnovative-ideas-financing-sdgs

Sachs, J., Schmidt-Traub, G., Kroll, C., Lafortune, G., \& Fuller, G. (2019). Sustainable Development Report 2019. Bertelsmann Stiftung and Sustainable Development Solutions Network (SDSN). Retrieved from https://s3.amazonaws.com/sustainabledevelopment.report/2019/2019_sustainable _development_report.pdf

Sihvart, M. (2017, 5 30). Blockchain - security control for government registers. Retrieved from E-estonia: https://e-estonia.com/blockchain-security-control-forgovernment-registers/

SolarCoin. (2019). Produce One Megawatt Hour, get One Free SolarCoin. Incentivizing a solar powered planet. Retrieved 5 10, 2020, from https://solarcoin.org/

Start Network. (2018). Blockchain - pilot II summary of learnings. Retrieved March 3, 2020, from https://startnetwork.app.box.com/s/utb8bq70g2tgo0rb6jgb167tjn9p1huh

Subhanij, T., \& Hasannudin, Z. (2020). Financing SDGs Under A New Normal: Challenges And Response To COVID-19 Pandemic. Retrieved 5 24, 2020, from ESCAP: https://www.unescap.org/blog/financing-sdgs-covid-19\#

Suri, T., \& Jack, W. (2016). The long-run poverty and gender impacts of mobile money. sciencemag.org . Retrieved 5 30, 2020, from https://www.jefftk.com/suri2016.pdf 
SWB. (2018). Congolese Entrepreneur Olivier Mukuta Wins the Nordic Startup Awards with his Blockchain Startup VipiCash. Retrieved 5 10, 2020, from Startups Without Borders: https://startupswb.com/congolese-entrepreneur-olivier-mukutawins-the-nordic-startup-awards-with-his-blockchain-startup-vipicash.html

Tinianow, A. (2019). Bombshell Report Finds Inclusion Lacking in the Blockchain Industry. Retrieved 5 31, 2020, from Forbes: https://www.forbes.com/sites/andreatinianow/2019/12/23/bombshell-reportfinds-inclusion-lacking-in-the-blockchain-industry/\#539c25ea9e1c

Trachy , A., \& Durant, E. (2017). Digital Diploma debuts at MIT. Retrieved 5 31, 2020, from http://news.mit.edu/2017/mit-debuts-secure-digital-diploma-using-bitcoinblockchain-technology-1017

Tran, S. (2020). Insurance Firms in China and Hong Kong Count on Blockchain to Fast Track Wuhan Coronavirus Claims Amid Outbreak. Retrieved 5 31, 2020, from Blockchain News: https://blockchain.news/analysis/insurance-firms-in-chinaand-hong-kong-count-on-blockchain-to-fast-track-wuhan-coronavirus-claimsamid-outbreak

UN DESA. (2020). Shared responsibility, global solidarity: responding to the socioeconomic impacts of COVID-19. Retrieved 5 24, 2020, from https://unsdg.un.org/sites/default/files/2020-03/SG-Report-Socio-EconomicImpact-of-Covid19.pdf

UN DESA. (2020). Sustainable Development Knowledge Platform. Retrieved 5 24, 2020, from https://sustainabledevelopment.un.org/vnrs/

UN Women. (2018). From where I stand: Using blockchain technology to empower women. Retrieved 5 10, 2020, from UNWomen: https://www.unwomen.org/en/news/stories/2018/2/from-where-i-stand-oliviermukuta

UN Women. (2018). UN Women and partners to pilot blockchain technology in humanitarian action. Retrieved 5 31, 2020, from https://www.unwomen.org/en/news/stories/2018/2/news-event-blockchaintechnology-and-humanitarian-action

UoM. (2017). University of Melbourne to issue recipient-owned blockchain records. $\begin{array}{lllll}\text { Retrieved } & 5 & 31, & \text { from }\end{array}$ https://about.unimelb.edu.au/newsroom/news/2017/october/university-ofmelbourne-to-issue-recipient-owned-blockchain-records 
Uport. (2019). Open Identity System for the Decentralized Web. Retrieved 5 10, 2019, from Uport: https://www.uport.me/

Vilar, H. (2019). Everest to supply KYC platform in Samoa for cross-border transactions. Retrieved 5 30, 2020, from Fintech Futures: https://www.fintechfutures.com/2019/03/everest-to-supply-kyc-platform-insamoa-for-cross-border-transactions/

World Bank. (2018). Poverty and Shared Prosperity 2018. Retrieved March 10, 2020, from https:/www.worldbank.org/en/publication/poverty-and-shared-prosperity

World Bank Group. (2017). The Global Findex Database 2017. Retrieved March 3, 2020, from https://globalfindex.worldbank.org/node

Young, D., \& Hammond, A. (2018). Can blockchain disrupt gender inequality? Retrieved 5 31, 2020, from https://blogs.worldbank.org/psd/can-blockchain-disrupt-genderinequality

Zhang, J. (2020). China start-up launches blockchain-based platform to improve donation efficiency amid virus crisis. Retrieved 5 31, 2020, from https://www.scmp.com/tech/blockchain/article/3050461/china-start-launchesblockchain-based-platform-improve-donation 